\title{
Article \\ Utilization of Aerobic Compression Composting Technology on Raw Mushroom Waste for Bioenergy Pellets Production
}

\author{
Wen Yi Chia ${ }^{1}$ D, Kit Wayne Chew ${ }^{2,3} * \mathbb{D}^{D}$, Cheng Foh Le ${ }^{4}$, Chelsea Siew Chyi Chee ${ }^{5}$, Mae See Luan Ooi ${ }^{5}$ \\ and Pau Loke Show ${ }^{1, *(D)}$
}

1 Department of Chemical and Environmental Engineering, Faculty of Science and Engineering, University of Nottingham Malaysia, Jalan Broga, Semenyih 43500, Selangor Darul Ehsan, Malaysia; wenyichia@gmail.com

2 School of Energy and Chemical Engineering, Xiamen University Malaysia, Jalan Sunsuria, Bandar Sunsuria, Sepang 43900, Selangor Darul Ehsan, Malaysia

3 College of Chemistry and Chemical Engineering, Xiamen University, Xiamen 361005, China

4 School of Biosciences, Faculty of Science and Engineering, University of Nottingham Malaysia, Semenyih 43500, Selangor Darul Ehsan, Malaysia; chengfoh.le@nottingham.edu.my

5 Mentari Alam EKO (M) Sdn Bhd (MAEKO), 192, Jalan LP 7/4, Kinrara Uptown, Taman Lestari Perdana, Seri Kembangan 43300, Selangor Darul Ehsan, Malaysia; chelsea@maeko.com.my (C.S.C.C.); mae@maeko.com.my (M.S.L.O.)

* Correspondence: kitwayne.chew@xmu.edu.my (K.W.C.); pauloke.show@nottingham.edu.my (P.L.S.)

\section{check for} updates

Citation: Chia, W.Y.; Chew, K.W.; Le, C.F.; Chee, C.S.C.; Ooi, M.S.L.; Show, P.L. Utilization of Aerobic Compression Composting Technology on Raw Mushroom Waste for Bioenergy Pellets Production. Processes 2022, 10, 463. https://doi.org/10.3390/pr10030463

Academic Editors: Worapon Kiatkittipong, Alok Kumar Patel and Jun-Wei Lim

Received: 25 October 2021

Accepted: 9 January 2022

Published: 24 February 2022

Publisher's Note: MDPI stays neutral with regard to jurisdictional claims in published maps and institutional affiliations.

Copyright: (C) 2022 by the authors. Licensee MDPI, Basel, Switzerland. This article is an open access article distributed under the terms and conditions of the Creative Commons Attribution (CC BY) license (https:// creativecommons.org/licenses/by/ $4.0 /)$.

\begin{abstract}
Raw mushroom waste has been an enormous solid waste, not only causing a huge cut on profit margin of mushroom industries but also leading to environmental pollution. Unfortunately, the current utilization methods, such as pharmaceutical extractions, are unable to keep up with the waste generation rate due to the large-scale mushroom production. Yet, the utilization of raw mushroom waste to produce biomass pellets for energetic purposes and the role of an electric composter on shortening the processing time remain unexplored. This is important because conventional composting, which takes a relatively long period (e.g., weeks to months), is less practical when it comes to commercial use of the biomass pellets. To explore this issue, an industrial composter with initial compost was utilized to process the raw mushroom waste, followed by pelletization. Extraction of the material inside the composter at different timing was carried out to determine the optimal processing time for optimal texture to form pellets. It was found that prolonged composting hour affected the pelletization process since moisture, which acts as a natural binder, reduced when the composting hour increased. The gross calorific value increased from $14.07 \mathrm{MJ} / \mathrm{kg}$ to $18.76 \mathrm{MJ} / \mathrm{kg}$ for raw mushroom waste and compost pellets at the fifth hour, respectively. This study revealed that the raw mushroom waste compost could serve as a valuable renewable energy source and that the production of energy-rich biomass compost fuel pellets without using any binder within a short composting duration is achievable with the aid of an in-vessel composter.
\end{abstract}

Keywords: biomass; energy utilization; pelletization; calorific value; composter

\section{Introduction}

Increased depletion of non-renewable energy resources has become a serious concern with the increased energy demand from population growth; there has been a focus on the need for novel alternative energy sources that are renewable and sustainable [1]. Environmental-friendliness has been consciously considered, since several global environmental issues, such as air pollution and global warming, have been triggered by the heavy consumption of fossil fuels [2]. The waste-to-energy approach has been a main research focus, as bioenergy development is reported to be sustainable in nature [3]. Generation of bioenergy is favourable, with minimal cost of operational expenses, reduction in waste volume and minimisation of waste disposal problems, as well as contribution to the economy, as the energy produced can be sold [4,5]. 
Generally, composting is considered as one of the prospective methods to recycle the organic portion of municipal solid waste, such as food waste, papers, and garden waste, through aerobic or anaerobic decomposition [6]. Compost produced is generally used to add total organic carbon to the soil, acting as soil amendment or fertiliser. However, beneficially applying compost on soil is not always possible, since there are variations in composting quality (i.e., the composts do not fulfil the local legal requirements for agricultural use) and market demand (i.e., the composts are overly produced or farmland area faces steady decline) $[7,8]$. In such cases, new uses for compost are being developed, including its valorisation as an energy source via combustion, pyrolysis or gasification [9].

The energetic use of compost has been investigated, including compost made from cattle feedlot manure [10], pig manure [11], forestry waste [12,13], shredded maize straw [14], food waste [15] and municipal solid waste [16]. It is important to determine the energy potential of the composts, since compost treatments result in different water content, as well as fuel characteristics [17]. The suitability of the composts as biofuel with or without additional pre-treatment and modification is also crucial. For instance, mixed compost made using passive heap technology studied by Malat'ák, et al. possessed a low calorific value $(8.51 \mathrm{MJ} / \mathrm{kg})$ and high ash content $(61.7 \%)$, while combustion with the addition of wood chips increased the calorific value to $13.14 \mathrm{MJ} / \mathrm{kg}$ [18].

Nevertheless, compost of raw mushroom waste has not been investigated for the energetic purpose. The undesirable parts of mushrooms are disposed of by mushroom and food industries; the volume drastically increases every year due to the exponential growth in mushroom consumption [19]. This underutilized cut-off waste makes up around 25 to $33 \%$ of fresh mushroom weight because of their poor palatability and tough texture [20,21]. Besides, irregular shape and dimensions of mushroom during cultivation and harvesting are also discarded [22]. This enormous solid waste not only causes a huge cut on the profit margin of mushroom industries but also leads to environmental pollution burdening mushroom producers and waste management authority [23]. According to Zou, et al., the current methods of utilizing raw mushroom waste such as pharmaceutical extractions and absorption material development are unable to keep up with the waste generation rate of large-scale mushroom production [24].

In addition, most of the studies in the literature used composts provided by composting plants or made via composting processes, which take a relatively long period (e.g., weeks to months). This is less practical when it comes to decentralized energy generation to solve the waste problems at its origin. The idea proposed in this study was to produce energetic material at the site of waste production for energy generation, which at least replaces a part of coal usage. With this approach, transportation and time could be saved without involving external composting plants, leading to cost reduction. Hence, organic waste from different industries and more advanced composting technology should be examined, but these are lacking in the reported literature. In this study, raw mushroom waste from the mushroom industry was used to generate compost pellets using an aerobic electric composter, where the processing time needed was investigated to greatly reduce the composting time. The aim of this study was to utilize this raw mushroom waste by measuring its energetic and pelletising potential with different short composting ages in order to achieve the most suitable and profitable operating conditions for the production of raw mushroom compost energy pellets.

\section{Materials and Methods}

\subsection{Materials, Composting and Pelletization}

Raw mushroom (Shiitake) waste from the food industry of mushroom soup powder production was kindly provided by Mentari Alam Eko (M) Sdn Bhd, together with initial compost with enzymes as well as a composter (MW30). The in-vessel composter with dimensions of $900 \times 680 \times 1300 \mathrm{~mm}$ was equipped with rotary blades and an air blower to provide good aeration $(54 \mathrm{~L})$, rotation and agitation of the compost $(8 \mathrm{rpm})$, producing uniform end compost product. This composter's function is to compost all type and 
sizes of food waste using microbial aerobic compression composting technology with an agitator system (Patent No.: P12015000732). Proper rotation with the good mixing, aeration and agitation of the compost was the efficient technique for the uniform product formation. The temperature inside the composting chamber was controlled at $55 \pm 2{ }^{\circ} \mathrm{C}$ using the sensors and heating functions equipped, regardless of the ambient temperatures. This is because a suitable thermophilic stage is essential for the inactivation of pathogens; temperature above $55{ }^{\circ} \mathrm{C}$ was demanded in the directives or guidelines [25].

In each processing or composting cycle, $30 \mathrm{~L}$ of raw mushroom waste, which was in dry pieces, as provided, was added into the composter containing the initial compost at shaft level (approximately $36 \mathrm{~L} ; 30 \%$ of the total chamber size of $120 \mathrm{~L}$ ), followed by $9 \mathrm{~L}$ of water, which was required due to the low moisture content $(<10 \%)$ of the raw mushroom waste. Material inside the composter, or compost, was extracted at different timing by collecting it at $1 \mathrm{~h}$ intervals, up to $6 \mathrm{~h}$. Short processing or composting time was possible, as the composter comes with patented aerobic microbial compression technology. The collected samples were processed into pellets by compacting and cutting into small pellets. The moisture content (MC) of the pellets was determined following ASTM E1756-08 [26] standard procedure by the loss of mass when heated in a drying oven at $105^{\circ} \mathrm{C}$ for $24 \mathrm{~h}$. These dried pellets were stored in a desiccator at room temperature. The remaining compost inside the composter was composted for $24 \mathrm{~h}$ and the product was discharged from the composter until the shaft level. The product that remained inside the composter was recycled in the next composting batch.

\subsection{Physicochemical Analysis}

\subsubsection{Pellet Density and FESEM Analysis}

The pellet weight was measured using a digital measuring balance with an accuracy of $0.01 \mathrm{~g}$ (Mettler Toledo, Greifensee, Switzerland). The height and diameter of the pellets in cylindrical shape were determined with a Vernier caliper (Mitutoyo, Kawasaki, Japan). The density of pellets was calculated by dividing the weight over the pellet volume and the average was taken from at least 10 sets of repetition. This method follows the EN ISO 17225 standard method. The surface morphology of the pellets, including microstructure and bonding behavior within pellets, was studied using a field emission scanning electron microscope (FESEM, FEI Quanta 400F, Oregon, USA).

\subsubsection{CHNS and FTIR Analysis}

The element compositions, carbon $(\mathrm{C})$, hydrogen $(\mathrm{H})$, nitrogen $(\mathrm{N})$ and sulphur $(\mathrm{S})$, were determined by a CHNS analyzer (Elementar, Langenselbold, Germany). The determination of these elements is important for the study of the carbon cycle, combustion and incineration technology, as well as soil organic materials. The functional group changes were analyzed by recording Fourier transform infrared (FT-IR) spectra of the pellet surface using a FT-IR spectrophotometer (Frontier, Perkin Elmer, Massachusetts, USA) with an average of 32 scans over $4000-400 \mathrm{~cm}^{-1}$.

\subsubsection{Proximate Analysis, Thermal Gravimetric and Calorific Value Analysis}

Combustion characterization of the pellets was conducted using a thermogravimetric analyzer (Perkin-Elmer STA6000, Massachusetts, USA). Approximately $10 \mathrm{mg}$ of each sample was heated from $30{ }^{\circ} \mathrm{C}$ to $800{ }^{\circ} \mathrm{C}$ at a heating rate of $20^{\circ} \mathrm{C} \mathrm{min}-1$ using an air flow of $100 \mathrm{~mL} \mathrm{~min}^{-1}$. Proximate analysis was carried out using the thermogravimetric analysis method [27]. The gross heating values (GCV) of the pellets were determined using a bomb calorimeter (Parr, Illinois, USA) from three replicates, following BS EN 14918. A sample of approximately $1 \mathrm{~g}$ was placed in a crucible linked to the fused wire for combustion to take place. Volumetric energy density of the pellets was calculated by multiplying the GCV with the mass density of the pellets. 


\subsubsection{Compression Strength, Mechanical Durability and Wettability Index}

Compression strength of the pellets was measured by a universal materials testing machine (Ametek Company, Leicester, UK). Before the compression, height and diameter of the pellets were measured. Using a $5 \mathrm{kN}$ load cell moving with a constant velocity of $1 \mathrm{~mm} / \mathrm{min}$, compression was carried out in axial direction individually to the pellet, which was laid vertically on a plate until collapsed. The maximum force recorded before breakage of the compressed pellet was taken as the compressive strength $(\mathrm{N})$ of the pellet, following the ASTM D695 method [28]. The tensile strength (MPa) of the pellets was calculated using the equation below.

$$
\mathrm{T}_{\mathrm{p}}=\frac{2 \mathrm{f}}{\pi \mathrm{ld}}
$$

where $\mathrm{f}$ is the maximum force, $\mathrm{d}$ is the pellet diameter, and $\mathrm{l}$ is the pellet length.

Mechanical durability of the pellets was measured through a drop test to determine the ratio of mass retained to the initial weight in percentage. Pellet samples after two weeks of storage were dropped from a height of $1.85 \mathrm{~m}$ on a metal plate [29].

Moisture resistance of the pellets was expressed as the wettability index (WI). Preweighed pellet was submerged in water for $30 \mathrm{~s}$ and then reweighed. The percentage of the difference in pellet weight before and after submerging from the initial weight was taken as the WI [30].

$$
\mathrm{WI}=\frac{\mathrm{m}_{\mathrm{a}}-\mathrm{m}_{\mathrm{b}}}{\mathrm{m}_{\mathrm{b}}} \times 100
$$

where $m_{b}$ and $m_{a}$ are the pellet weight $(\mathrm{g})$ before and after submerging, respectively.

\section{Results and Discussion}

\subsection{Characterization of Raw Materials and Pellets}

Mushrooms generally possess a high nutritional value and are rich in protein, including an important content of fiber and essential amino acids. Shiitake consists of dietary fiber with soluble and insoluble structures, the former of which contains $\beta$-glucans and proteins; the latter contains polyuronide (acidic polysaccharide), hemicellulose, chitin, lignin and $\beta$-glucan chains with heterosaccharide [31]. The chemical properties of raw mushroom waste and the composted mushroom waste are shown in Table 1. Raw mushroom waste contains a high content of organic matter; the compost pellets at all time periods showed a higher carbon content, which is desirable for energy and heating application.

Table 1. Properties of raw mushroom waste and compost extracted at $1 \mathrm{~h}$ (B1), $2 \mathrm{~h}$ (B2), $3 \mathrm{~h}$ (B3), $4 \mathrm{~h}$ (B4) and $5 \mathrm{~h}$ (B5).

\begin{tabular}{ccccccc}
\hline Ultimate Analysis (\%) & Raw Mushroom Waste & B1 & B2 & B3 & B4 & B5 \\
\hline Carbon & 36.44 & 42.91 & 41.46 & 42.30 & 41.67 & 42.09 \\
\hline Hydrogen & 6.83 & 6.46 & 6.53 & 6.54 & 6.54 & 6.54 \\
\hline Nitrogen & 5.36 & 3.96 & 3.94 & 4.04 & 4.02 & 4.09 \\
\hline Sulphur & 0.37 & 0.26 & 0.27 & 0.26 & 0.26 & 0.25 \\
\hline C/N ratio & 6.80 & 10.84 & 10.52 & 10.47 & 10.37 & 10.29 \\
\hline
\end{tabular}

The composting process involves the reduction of organic substances in the compost feed into decomposed materials [32]. The higher carbon content in compost as compared to the raw mushroom waste might be due to the addition of the initial compost with enzymes. It can be seen that there was reduction in carbon with the increase composting hour through the rapid composting process performed by the electric composter. On the other hand, there was a slight drop in hydrogen and sulphur content, which were likely consumed during the composting process. The nitrogen content decreased by $23.7-26.5 \%$ for the raw mushroom waste, as nitrogen is consumed during the composting process. 
To be specific, there was a loss of $\mathrm{NH}_{4}{ }^{+}$during the initial stage of the composting process by $\mathrm{NH}_{3}$ volatilization or with nitrification, followed by a subsequent loss of $\mathrm{NO}_{3}{ }^{+}$via denitrification [33]. The relatively low content of sulphur indicates that the combustion of the samples is environmentally compatible [24]. On the other hand, the $\mathrm{H} / \mathrm{C}$ ratio decreased from 0.19 to 0.15 after composting, where lower $\mathrm{H} / \mathrm{C}$ showed better fuel quality and higher thermal efficiency [34].

There was no significant difference between any CHNS compositions for the raw mushroom waste compost of 1-5 h. However, it can be observed that the carbon-to-nitrogen ratio (C:N ratio) gradually decreased due to the release of the organic matter content [35]. The apparent difference was in the observation of the compost texture becoming drier with each subsequent hour of composting. The in-vessel composter was able to complete the composting process in a well-mixed condition and short duration. The study on the effect of time showed that the results were comparable for all durations; extending the composting period mainly affected the moisture content within the compost.

The FTIR spectra of raw mushroom waste and raw mushroom waste compost pellets of different hours are shown in Figure 1. The characteristics of the compost are mainly derived from the raw mushroom residue, which contains carbohydrates, nitrogen compounds that include crude protein and decomposition products, and aliphatic compounds that are mainly crude fat. These compounds are mainly decomposed to carbon dioxide, ammonium ion, amide nitrogen, nitrate ion, protein and its decomposition products [36]. The FTIR spectrum of raw mushroom waste showed peaks corresponding to different functional groups, including carbohydrates such as cellulose, hemicellulose and lignin, proteins, silicate minerals and amide compounds, where the peak at $3253 \mathrm{~cm}^{-1}$ corresponds to $\equiv \mathrm{C}$-H stretch; $2927 \mathrm{~cm}^{-1}$ and $2853 \mathrm{~cm}^{-1}$ corresponds to aliphatic C-H stretch; $1635 \mathrm{~cm}^{-1}$ corresponds to $\mathrm{C}=\mathrm{O}$ stretch; $1148 \mathrm{~cm}^{-1}$ and $1021 \mathrm{~cm}^{-1}$ corresponds to $\mathrm{C}-\mathrm{O}$ stretch [37].

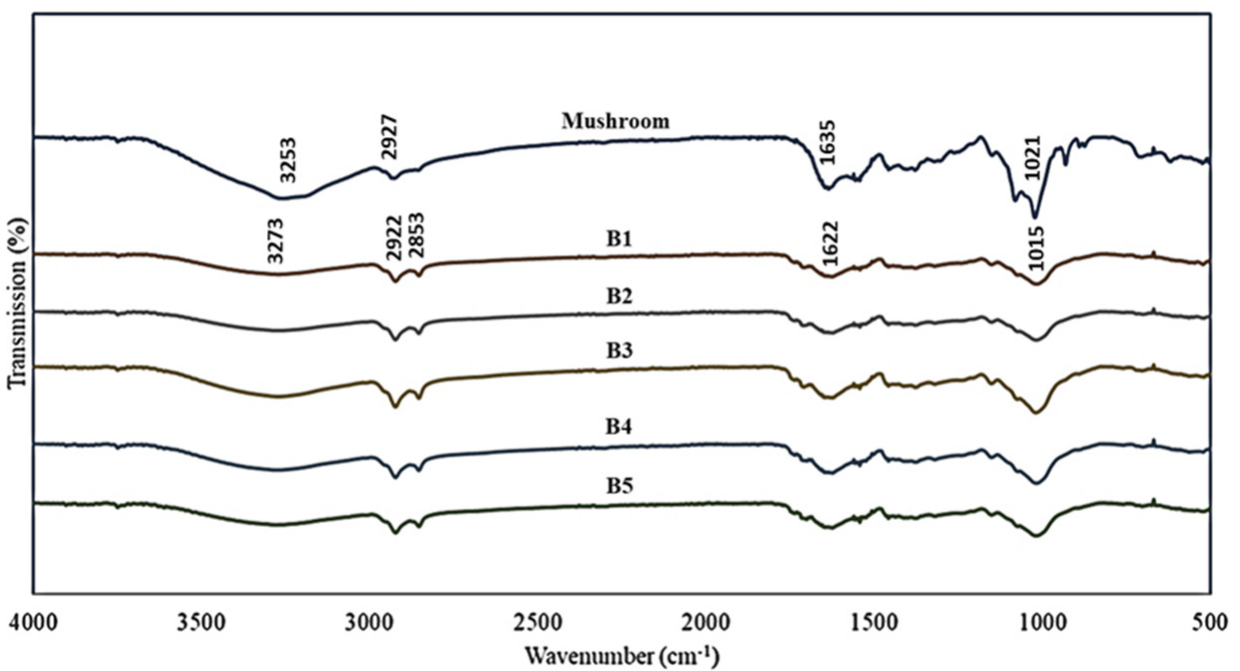

Figure 1. FTIR spectra of raw mushroom waste and mushroom compost pellets extracted at different composting hour.

There was an obvious reduction in the absorption peaks when comparing the FTIR spectra of raw material and compost pellets, while there was just a gradual reduction among the compost pellets at different composting hour. Firstly, there is a strong band detection between 930 and $1148 \mathrm{~cm}^{-1}$ which corresponds to the carbohydrate or polysaccharides substance. Since polysaccharides are an important component in raw mushroom caused by the starchy fibers of organic waste plant materials, there exists a sharp peak [36]. The composted pellets still retain raw mushroom as its main material and, hence, the peak is observed for all durations. The intensity of peaks at $1021 \mathrm{~cm}^{-1}$ decreased greatly with maturation due to the progressive consumption of polysaccharides and stabilization [38]. 
Another band at $1635 \mathrm{~cm}^{-1}$ in the raw mushroom is likely the presence of carboxylates and $\mathrm{C}=\mathrm{C}$ from aromatics and alkenes. Mushrooms contain many functional properties, and the composition of carboxylic acid has contributed to the peak. Composted mushroom still showed a slight peak at the respective band. The band at $1635 \mathrm{~cm}^{-1}$, which was also related to lignin, experienced a relative decrease after composting [36]. The presence of a band around $2927 \mathrm{~cm}^{-1}$ in the mushrooms is attributed to the humic acid component. Humic acid is widely used for the cultivation of mushroom, as it helps to promote its growth; the raw mushroom waste was likely to contain traces of the humic acid from cultivation steps. While the range of 2940 to $2850 \mathrm{~cm}^{-1}$ indicated the saturation of humic acid, which occurs during the composting process, the peaks were observed for composted fractions at all durations. The development of the band at $2927 \mathrm{~cm}^{-1}$ was also used as an indicator of organic matter decomposition [39]. The strength at the peak of $2927 \mathrm{~cm}^{-1}$ had weakened compared to the raw mushroom waste, which could have been caused by losing specific constituents in cell walls, such as pectin [40].

The range of $\mathrm{O}-\mathrm{H}$ and $\mathrm{N}-\mathrm{H}$ stretching vibration band was obtained around $3200-3300 \mathrm{~cm}^{-1}$, representing the intermolecular hydrogen bonding that corresponds to phenolic groups. Phenolic compounds are the main components that support the antioxidant activity from the raw mushroom extract, hence, the peak is observed for raw mushroom waste; however, the peak declines for composted fractions, as phenolic compounds tend to degrade at temperatures higher than $50^{\circ} \mathrm{C}$, which occurs during the composting step. Additionally, the peak at $3253 \mathrm{~cm}^{-1}$, which could refer to the presence of a hydrogen band in cellulose, changed from a relatively sharp peak to a gentle peak, indicating the degradation of lignocellulose [41,42].

\subsection{Combustion Characteristics}

Proximate analysis was carried out for both raw mushroom waste and compost pellets produced. The results of raw mushroom waste are similar to results by Zou, et al., who found that the mushroom stipe contained $8.19 \%$ moisture, $73.27 \%$ volatile matter, $13.83 \%$ fixed carbon and $4.72 \%$ ash [24]. The samples in the reported study [24] were dried before analysis, while, in the present study, raw mushroom waste was analyzed in its original form; hence, there are slight differences in terms of moisture content and higher heating value. According to Ahmad, et al., moisture content of less than $10 \%$ in lignocellulosic biomass is considered as suitable for combustion [43]. It is known that high volatile matter content makes biomass a highly reactive fuel with a faster combustion rate, while fixed carbon-which is the remaining solid fuel after volatile matter-acts as a main energy generation for combustion [44]. The volatile matter (Table 2) was found to increase and decrease, respectively, after the composting process. Some of the substrate and compounds were broken down during the decomposition; hence, the amount of volatile matter was lower during the early stages of the composting process. The highest volatile matter in B5 indicated that it would burn vigorously with high reactivity and show low combustion enthalpies during direct combustion [45].

Table 2. Proximate analysis, gross heating value, mass and energy densities of raw mushroom waste compost pellets prepared at different composting hour.

\begin{tabular}{cccccccc}
\hline Sample & $\begin{array}{c}\text { Moisture } \\
(\mathbf{\%})\end{array}$ & $\begin{array}{c}\text { Volatile } \\
\text { Matter (\%) }\end{array}$ & $\begin{array}{c}\text { Fixed } \\
\text { Carbon } \mathbf{( \% )}\end{array}$ & $\begin{array}{c}\text { Ash } \\
\mathbf{( \% )}\end{array}$ & $\begin{array}{c}\text { GCV } \\
(\mathbf{M J} / \mathbf{k g})\end{array}$ & $\begin{array}{c}\text { Mass Density } \\
\left(\mathbf{k g} / \mathbf{m}^{\mathbf{3}}\right)\end{array}$ & $\begin{array}{c}\text { Energy Density } \\
\left(\mathbf{G J} / \mathbf{m}^{\mathbf{3}}\right)\end{array}$ \\
\hline Raw mushroom waste & 9.81 & 74.02 & 13.83 & 2.10 & 14.07 & - & - \\
\hline B1 & 5.47 & 64.52 & 21.78 & 8.18 & 18.85 & 1055.46 & 19.90 \\
\hline B2 & 6.06 & 73.92 & 15.18 & 4.94 & 19.08 & 1076.70 & 20.54 \\
\hline B3 & 2.64 & 65.01 & 23.82 & 8.58 & 18.90 & 1099.71 & 20.78 \\
\hline B4 & 5.06 & 62.61 & 25.76 & 6.43 & 18.83 & 1107.67 & 20.86 \\
\hline B5 & 3.33 & 75.42 & 13.50 & 7.17 & 18.76 & 1130.37 & 21.21 \\
\hline
\end{tabular}


The same trend was observed for the fixed carbon content, where durations of 1-4 $\mathrm{h}$ showed a good increase in fixed carbon; however, the carbon content dropped to a lower value than the control at a duration of $5 \mathrm{~h}$. Continuous processing of compost within the invessel system may lead to exposure of high temperatures that are a result of the continuous operation and decomposition. These high temperatures will eventually decompose the organic properties of compost; hence, there was a loss of carbon content. The ash content of all the compost pellets was classified as a low ash coal based on the Chinese National Standard (Classification for quality of coal. Part 1: Ash content, GB/T 15224.2-2010) and International Standard (Classification of coals, ISO 11760-2005) [46]. The ash contents for the compost pellets fall in the range of $4.936-8.582 \%$. The ash content increased from the initial ash content in raw mushroom waste. This is due to the decomposition process in composting, which produces ash compounds.

The mass density was increased after the pelletization process and increased for every hour. According to Pua, et al., high moisture content in biomass tends to cause reduction in pellet density and raw fibers of low density will cause an issue in product storage and transportation [44,47]. Hence, fuel pellets that have high bulk and energy density are favorable to save space and minimize expenses. According to European guidelines, the accepted standard density range of a single pellet is between 1000 to $1400 \mathrm{kgm}^{-3}$ [48], making pellet density in this study, with a density range of $1055.46-1130.37 \mathrm{kgm}^{-3}$, acceptable. The mass density of the compost pellets showed an increasing trend with longer composting duration. During the composting process, the raw mushroom waste was broken down into smaller fractions by the substrates and bacteria; hence, a longer composting period will result in more parts of the fine compost material. The pelletization of finer compounds might lead to higher density, as it is easier to compact fine powdery materials, although it is not significant [49].

Calorific value can indicate the combustion properties of a pellet. Lower composting hours were selected as lower composting degradation, which means that a higher content of organic matter gives higher heating values and that the heating value must be reduced after the active composting process [16]. The gross calorific value (GCV) of low-rank coals according to the Chinese National Standard (Classification for quality of coal. Part 3: Calorific value, GB/T 15224.32010) is below $16.30 \mathrm{MJ} / \mathrm{kg}$ [46]; the results in Table 2 showed that all compost pellets possessed higher GCV. Once densified, these pellets can show a high GCV value, making them suitable as heating sources. The GCV for all time durations are comparable, and are significantly higher than the pellets made from other composts reviewed by Chia, et al. [6]. The increase in density and similar range of GCV also resulted in increasing energy density of the compost pellets, in line with the composting time. The energy density values were similar to torrefied biomass pellets and coal, which reaches $18 \mathrm{GJ} / \mathrm{m}^{3}$ and exceeds $20 \mathrm{GJ} / \mathrm{m}^{3}$, respectively, while raw biomass typically has an energy density of 10 to $11 \mathrm{GJ} / \mathrm{m}^{3}$ [50,51].

The combustion process and thermal stability of the resulting pellets from compost extracted at the fifth hour were investigated with a thermogravimetric analyzer, as shown in Figure 2. The pellet faced three stages of mass loss process, which were between temperatures of 100 to $200{ }^{\circ} \mathrm{C}, 200$ to $400{ }^{\circ} \mathrm{C}$, and 400 to $600{ }^{\circ} \mathrm{C}$, respectively. Mass loss in the first stage, which is about $3.87 \%$, may be due to evaporation of moisture and loss of a small number of volatile substances. It can be seen that the moisture content was low as the pellets were dried after the pelletization. There might also be slight moisture loss during the pelletization. Mass loss, about $49.37 \%$, in the second stage, called the volatile component combustion stage, is the main stage of weight loss because the main chemical components, such as cellulose, hemicellulose and other organic functional groups in the sample faced gradual degradation. To be specific, hemicellulose, which has low polymerization degree, should break first, while cellulose faced a partly depolymerizing reaction [24]. The maximum weight loss was estimated at $9.97 \% / \mathrm{min}$ at $289.46^{\circ} \mathrm{C}$. Lastly, degradation of stable lignin is the main cause of the mass loss in the third stage (36.56\%), which is the oxidation stage of fixed carbon. The TG curve tends to be flat after $600{ }^{\circ} \mathrm{C}$ 
as the combustion was basically completed with remaining residual ash and other nondecomposable substances [52].

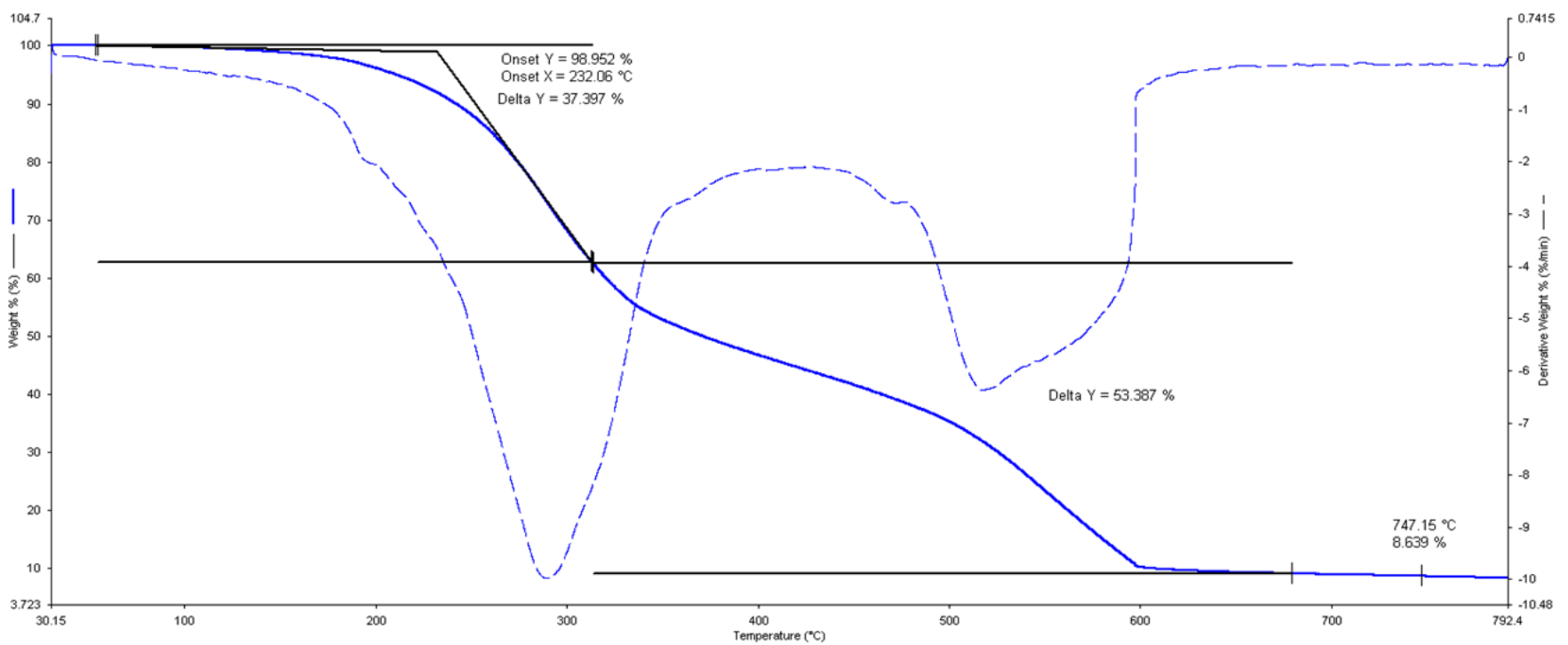

Figure 2. Thermal degradation (TGA) and differential mass loss (DTG) curve of the pellets prepared from compost extracted at $5 \mathrm{~h}$.

\subsection{Mechanical Properties}

The composts were pelletized using a small extruder pelletizer into pellets of around $5.5 \pm 0.1 \mathrm{~mm}$ diameter and $20 \pm 0.15 \mathrm{~mm}$ length. Pellets that were below this range were sieved and removed. The pellets produced were able to form into the size fitting to ISO/DIS 17225-6, which biofuel pellet refers to densified biofuel in a cylindrical form, with a diameter up to $25 \mathrm{~mm}$ and length between $5 \mathrm{~mm}$ to $40 \mathrm{~mm}$, produced by biomass compression. The physico-chemical properties of the compost pellet at different durations are presented in Table 3. The moisture content of the compost was found to decrease proportionally with the composting time. A longer duration of composting would subject the materials to more heat and decomposition, which will result in lower final moisture content [53]. The resultant pellets showed a similar trend of decreasing moisture content with an increasing composting time interval. A minimum amount of moisture is required to enhance the particle adhesion during pelletization. Generally, organic fibrous material can contain a moisture content of $16-28 \%$; however, when the moisture content drops to $16-18 \%$, the pellet mill dies tend to choke, which is not desirable [54]. Meanwhile, Zajonc, et al. reported that the optimum moisture value is within 25 to $30 \%$ and that higher values are not suitable in the production of pellets, although this might change depending on the composition of compost [30].

Table 3. Moisture content, compressive and tensile strength, durability and wettability index of raw mushroom waste compost pellets prepared at $1 \mathrm{~h}$ (B1), $2 \mathrm{~h}$ (B2), $3 \mathrm{~h}$ (B3), $4 \mathrm{~h}$ (B4) and $5 \mathrm{~h}$ (B5).

\begin{tabular}{cccccc}
\hline Sample & $\begin{array}{c}\text { Moisture Content } \\
\text { before Pelletization } \\
(\mathbf{\%} w \mathbf{w})\end{array}$ & $\begin{array}{c}\text { Impact Resistance } \\
\mathbf{( \% )}\end{array}$ & $\begin{array}{c}\text { Maximum } \\
\text { Compressive } \\
\text { Force (N) }\end{array}$ & $\begin{array}{c}\text { Tensile Strength } \\
\mathbf{( M P a )}\end{array}$ & $\begin{array}{c}\text { Wettability Index } \\
\mathbf{( \% )}\end{array}$ \\
\hline B1 & $29.62 \pm 1.06$ & $99.90 \pm 0.09$ & 266.27 & 1.56 & 7.93 \\
\hline B2 & $27.88 \pm 0.89$ & $99.91 \pm 0.08$ & 255.73 & 1.50 & 8.65 \\
\hline B3 & $26.46 \pm 0.59$ & $99.84 \pm 0.11$ & 258.68 & 1.52 & 8.94 \\
\hline B4 & $25.22 \pm 0.70$ & $99.90 \pm 0.03$ & 302.62 & 1.77 & 10.77 \\
\hline B5 & $24.34 \pm 0.73$ & $99.94 \pm 0.04$ & 280.84 & 1.65 & 13.70 \\
\hline
\end{tabular}


The pellets with lower moisture content also showed signs of surface crack in the surface morphology study, as shown in Figure 3. Compost pellets made from $5 \mathrm{~h}$ of composting show large defects on the surface of the pellets, while, from 2-3 h of composting, minor defects were observed. The presence of a gap in Figure 3 e showed poor adhesion, which may cause reduction of stiffness and deformation, leading to particle movement within the pellet matrix and making the pellets less durable mechanically [55]. The moisture content plays a significant role in pellet production; a small decrease in percentage (up to $5.82 \%$ ) can affect the overall mechanical stability of pellets [54]. Hence, further extraction of compost at the sixth hour was avoided to produce pellets with good mechanical durability without the addition of any binder. This is because pellets with an ideal combination of mechanical shock resistance and calorific value are the most suitable for commercialization.
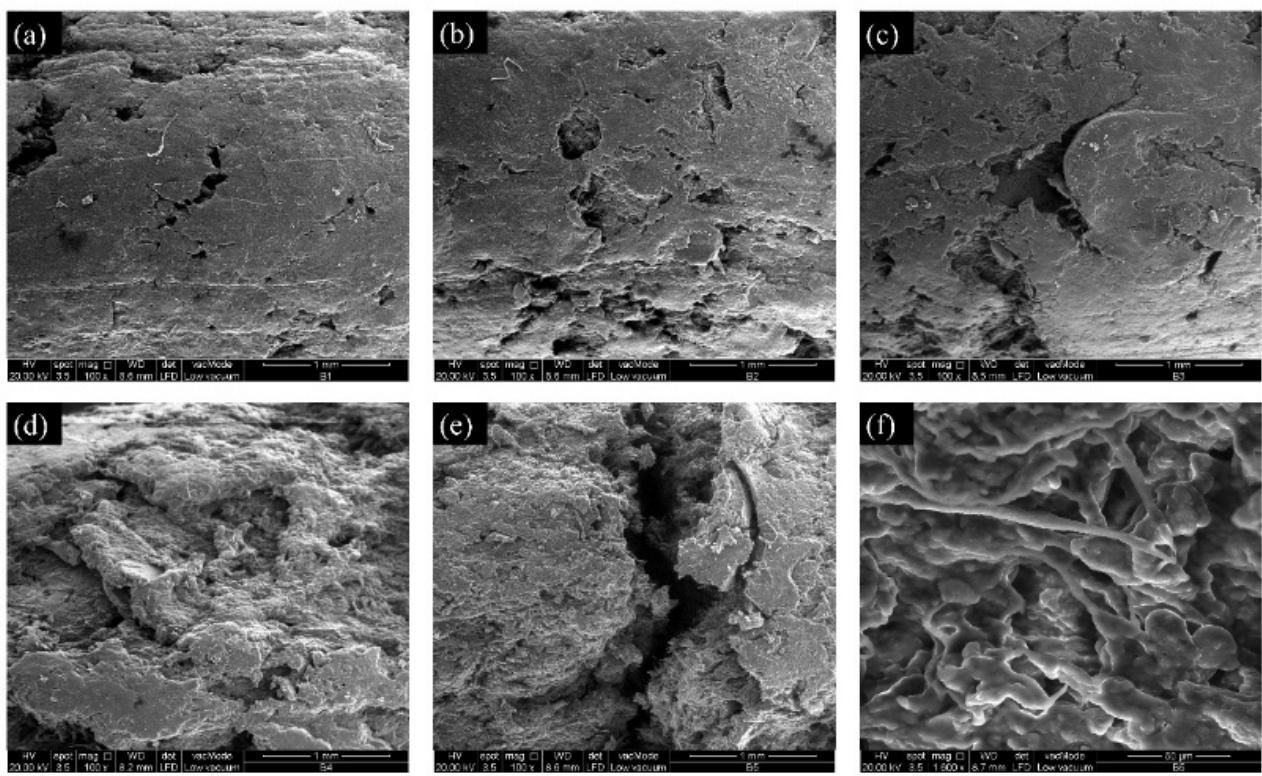

Figure 3. FESEM images on the compost pellet surface at $1 \mathrm{~mm}$ for compost extracted at $1 \mathrm{~h} \mathrm{(a),}$

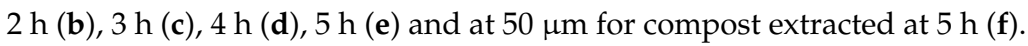

The impact resistance of the pellets was found to be above $99.8 \%$ for compost pellets from all durations of composting. This indicates that the compost pellet exhibited high resistance to external force and would be able to withstand the load during transportation and handling [56]. Most pellets were able to show good impact resistance as the pellets were densified and the structure of the pellet showed a closely packed interconnected structure, which held its strength when subjected to load [55]. During the biomass densification or pelletization, the formation of a solid bridge, mechanical interlocking bonds and attraction forces between solid particles, is the most important binding mechanism, because the solid bridges, which were shown in Figure 3f, mainly created the bonding between particles [57].

The analysis on the compressive force and tensile strength of the compost pellets showed that samples at $4 \mathrm{~h}$ and $5 \mathrm{~h}$ had better strength. At $1 \mathrm{~h}$ duration, it is likely that the composting process has not fully begun; hence, the raw mushroom waste compost extracted was at the beginning stage of composting and retained a major part of the initial raw mushroom waste properties. While, for the duration of $2-3 \mathrm{~h}$, the composting process was in progress and its extraction led to slightly incomplete composting. Raw mushroom contains phenolic compounds, which require more composting time and more effort by bacteria to break down, as their chemical structure is complex [58]. Nevertheless, the raw material in this study, which is the raw mushroom waste, was in small pieces that would accelerate the composting process, as there was increased surface area with more susceptibility to degradation [6]. While, for 4 and $5 \mathrm{~h}$ of composting, the pellets produced showed an increase of $13.7 \%$ and $13.5 \%$ for compressive strength and tensile strength, respectively. At this duration, the compost extracted had been processed for a more sufficient duration 
and the compost exhibited suitable properties for pellet making. Overall, the compressive strength of the raw mushroom waste compost pellets was higher than compost pellets produced with municipal solid wastes with 44 to $113 \mathrm{~N}$ [57], and comparable to compost pellets made from food waste and green waste with additives, which exhibited the highest strength up to $297.1 \mathrm{~N}$ [28].

For the wettability index (WI), the increasing duration of composting produced pellets of increasing WI. This trend is in line with the initial moisture content of the pellets. Each pellet has a saturation point for moisture and, hence, the pellets with lower moisture were able to uptake more liquid before achieving saturation. Composts from longer duration are also more porous due to the decomposition step, which transforms the compost into more porous-like structures. The availability of pores allows more fluid to be absorbed within the pellet, which is seen from the results. A work by Zajonc, et al. showed that compost that were drier exhibited higher WI as well. Comparing to average $18 \% \mathrm{WI}$ and the individual WI results with $<30 \%$ moisture in the study by Zajonc, et al., the compost pellets in the present study generally exhibited lower WI [30]. The WI between 7.93 to $13.70 \%$ indicates that the pellets can absorb up to $13.7 \%$ moisture content with humid situations. Besides, the WI of compost pellets reported in a study by Chew, et al. was between $18.1 \%$ and $19.7 \%$ which were higher as well. The low WI presented in this study is desirable to ensure that the compost pellets could be stored in appropriate conditions within an adequate period without worry on deterioration [28].

Based on the overall observation, the suitable timing for the composting is most favorable at $4 \mathrm{~h}$. Compost from $4 \mathrm{~h}$ of processing showed the highest compressive strength and tensile strength, with high impact resistance and feasible wettability index. For the pelletized compost, at $4 \mathrm{~h}$ of processing, the compost pellets showed reasonable moisture content, high fixed carbon and calorific value, with high mass density and energy density, falling slightly below that of $5 \mathrm{~h}$. The duration of 1-2 h of composting did not show sufficient decomposition of the raw mushroom waste, while $3 \mathrm{~h}$ of composting exhibited qualities of compost that were much lower than 4-5 h. The duration of $4 \mathrm{~h}$ is considered as the most satisfactory, as the design of the electric composter is supposed to function as a rapid composter to reduce the overall composting time, which, on average, could take less than $24 \mathrm{~h}$ for a closed composting system $[59,60]$. This reduction in time needed for composting and the evaluation of the subsequent pellets characteristics, which are suitable as biomass pellets, indicate the effectiveness of the rapid electric composter design.

Nevertheless, the compost investigated in this study was not regarded as matured compost since fertilizing potential was not the focus to be examined and the curing process was not carried out. The main objective of this study was to generate pellets from the abundantly available raw mushroom waste using an electric composter and to analyze their energetic potential with the variable of different composting hours. Even though composting using this MW30 composter was said to be mature towards $24 \mathrm{~h}$, short composting hours were experimented to reduce the processing time, retain the carbon content that reduces over composting and reduce the moisture loss due to continuous heat exposure in the composter. The aerobic electric composter was able to process and decompose the raw organic waste into sludgy or powdery material that can be pelletized within the short composting hours. Comparing the results of raw mushroom waste and compost pellets prepared, it can be observed that compost pellets exhibited higher carbon content, lower $\mathrm{H} / \mathrm{C}$ ratio, lower sulphur content, lower moisture content, higher gross calorific value and higher density, all of which indicate better fuel quality. Even though the ash contents were higher after composting, they were still within the standards for low ash coal. The insignificant results between composting hours might be because the difference in composting hours was too small, in that only five hours were examined. However, moisture content at $6 \mathrm{~h}$ was too low to form pellets with good form and shape, hence it was not included. Besides, the insignificant results of trends with time might be due to the large amount of heterogenous samples despite the number of replicates of at least three sets. However, 
from the view of much higher tensile strength, wettability index and energy density, compost pellets of $4 \mathrm{~h}$ and $5 \mathrm{~h}$ are deemed more suitable than the ones of 1-3 $\mathrm{h}$.

\section{Conclusions}

Raw mushroom waste was processed using an aerobic composting machine to a compostlike material, which was then extracted at a different processing hour to generate pellets for energetic purpose. Raw mushroom waste was used as it is abundantly available from the food factory; it would be beneficial if factories could possess equipment to process the raw mushroom waste to an energy fuel material to replace the depleting energy sources. The results presented that the mushroom compost pellets contained a low sulphur content and a low $\mathrm{H} / \mathrm{C}$ ratio which indicated better environmental compatibility and thermal efficiency, respectively. Besides, thermal and combustion properties were potential for all the pellets due to the high volatile matter content, low ash content and high calorific value $(\mathrm{GCV}>18.76 \mathrm{MJ} / \mathrm{kg})$. Additionally, the pellets exhibited excellent mechanical properties, especially the impact resistance, as high as $99.94 \%$, and the wettability index, between 7.93 to $13.70 \%$, which were much lower than other pellets in the literature. This study concluded that a short processing period $(<5 \mathrm{~h})$ was sufficient to generate material feed for biomass pelletization that can be utilized as a solid fuel source. This study also suggests the implementation of on-site waste processing to generate valuable material with energy purposes. Nevertheless, combustion test analysis would be beneficial to study boiler efficiency using the end-product as a biofuel source to improve the overall economics.

Author Contributions: Conceptualization, W.Y.C., C.S.C.C. and M.S.L.O.; methodology, W.Y.C. and M.S.L.O.; software, W.Y.C.; validation, W.Y.C. and K.W.C.; formal analysis, W.Y.C. and K.W.C.; investigation, W.Y.C.; resources, C.S.C.C. and M.S.L.O.; data curation, W.Y.C. and K.W.C.; writingoriginal draft preparation, W.Y.C. and K.W.C.; writing-review and editing, W.Y.C., K.W.C. and C.F.L.; visualization, W.Y.C.; supervision, K.W.C., C.F.L. and P.L.S.; project administration, P.L.S.; funding acquisition, K.W.C. and P.L.S. All authors have read and agreed to the published version of the manuscript.

Funding: This research was funded by Mentari Alam EKO (M) Sdn Bhd (MAEKO), Fundamental Research Grant Scheme, Malaysia [FRGS/1/2019/STG05/UNIM/02/2] and MyPAIR-PHCHibiscus Grant [MyPAIR/1/2020/STG05/UNIM/1]. This work was also supported by Xiamen University Malaysia (XMUM) under the XMUM Research Fund (Grant number: XMUMRF/2021C7/IENG/0033) and Hengyuan International Sdn. Bhd.

Acknowledgments: We would like to express appreciation to Mentari Alam EKO (M) Sdn Bhd (MAEKO) for providing technical support, composting machine and materials used.

Conflicts of Interest: The authors declare no conflict of interest.

\section{References}

1. Khalil, M.; Berawi, M.A.; Heryanto, R.; Rizalie, A. Waste to energy technology: The potential of sustainable biogas production from animal waste in Indonesia. Renew. Sustain. Energy Rev. 2019, 105, 323-331. [CrossRef]

2. Abdeshahian, P.; Lim, J.S.; Ho, W.S.; Hashim, H.; Lee, C.T. Potential of biogas production from farm animal waste in Malaysia. Renew. Sustain. Energy Rev. 2016, 60, 714-723. [CrossRef]

3. Srivastava, R.K.; Shetti, N.P.; Reddy, K.R.; Aminabhavi, T.M. Sustainable energy from waste organic matters via efficient microbial processes. ScTEn 2020, 722, 137927. [CrossRef]

4. Dhanya, B.S.; Mishra, A.; Chandel, A.K.; Verma, M.L. Development of sustainable approaches for converting the organic waste to bioenergy. ScTEn 2020, 723, 138109. [CrossRef]

5. Iqbal, M.W.; Kang, Y. Waste-to-energy supply chain management with energy feasibility condition. J. Clean. Prod. 2021, 291, 125231. [CrossRef]

6. Chia, W.Y.; Chew, K.W.; Le, C.F.; Lam, S.S.; Chee, C.S.C.; Ooi, M.S.L.; Show, P.L. Sustainable utilization of biowaste compost for renewable energy and soil amendments. Environ. Pollut. 2020, 267, 115662. [CrossRef]

7. Jeong, K.-H.; Lee, D.-j.; Lee, D.-H.; Lee, S.-H. Combustion characteristics of cow manure pellet as a solid fuel source. J. Korea Org. Resour. Recycl. Assoc. 2019, 27, 31-40. [CrossRef]

8. Sardarmehni, M.; Levis, J.W.; Barlaz, M.A. What Is the Best End Use for Compost Derived from the Organic Fraction of Municipal Solid Waste? Environ. Sci. Technol. 2021, 55, 73-81. [CrossRef] [PubMed] 
9. Díaz, M.J.; Ruiz-Montoya, M.; Palma, A.; de-Paz, M.-V. Thermogravimetry Applicability in Compost and Composting Research: A Review. Appl. Sci. 2021, 11, 1692. [CrossRef]

10. Sweeten, J.M.; Heflin, K.; Annamalai, K.; Auvermann, B.W.; McCollum, F.T.; Parker, D.B. Combustion-Fuel Properties of Manure or Compost from Paved vs. Un-Paved Cattle Feedlots. In Proceedings of the 2006 ASAE Annual Meeting, Portland, OR, USA, 9-12 July 2006; p. 1.

11. Troy, S.M.; Nolan, T.; Leahy, J.J.; Lawlor, P.G.; Healy, M.G.; Kwapinski, W. Effect of sawdust addition and composting of feedstock on renewable energy and biochar production from pyrolysis of anaerobically digested pig manure. Biomass Bioenergy 2013, 49, 1-9. [CrossRef]

12. Skanderova, K.; Malat'ák, J.; Bradna, J.J. Energy use of compost pellets for small combustion plants. Agron. Res. 2015, 13, 413-419.

13. Malat'ák, J.; Bradna, J.; Velebil, J. Combustion of briquettes from oversize fraction of compost from wood waste and other biomass residues. Agron. Res. 2016, 14, 525-532.

14. Kopeć, M.; Gondek, K.; Mierzwa-Hersztek, M.; Zaleski, T. Effect of the composting process on physical and energetic changes in compost. Acta Agrophys. 2016, 23, 607-619.

15. Yeo, J.; Oh, J.-I.; Cheung, H.H.L.; Lee, P.K.H.; An, A.K. Smart Food Waste Recycling Bin (S-FRB) to turn food waste into green energy resources. J. Environ. Manag. 2019, 234, 290-296. [CrossRef] [PubMed]

16. Doña-Grimaldi, V.M.; Palma, A.; Ruiz-Montoya, M.; Morales, E.; Díaz, M.J. Energetic valorization of MSW compost valorization by selecting the maturity conditions. J. Environ. Manag. 2019, 238, 153-158. [CrossRef]

17. Vandecasteele, B.; Boogaerts, C.; Vandaele, E. Combining woody biomass for combustion with green waste composting: Effect of removal of woody biomass on compost quality. Waste Manag. 2016, 58, 169-180. [CrossRef]

18. Malat'ák, J.; Bradna, J.; Velebil, J.; Gendek, A.; Ivanova, T. Evaluation of dried compost for energy use via co-combustion with wood. Agron. Res. 2018, 16, 157-166. [CrossRef]

19. Wang, C.-Y. A Review on the Potential Reuse of Functional Polysaccharides Extracted from the By-Products of Mushroom Processing. Food Bioprocess Technol. 2020, 13, 217-228. [CrossRef]

20. Chou, W.-T.; Sheih, I.-C.; Fang, T.J. The Applications of Polysaccharides from Various Mushroom Wastes as Prebiotics in Different Systems. J. Food Sci. 2013, 78, M1041-M1048. [CrossRef]

21. Li, S.; Wang, A.; Liu, L.; Tian, G.; Wei, S.; Xu, F. Evaluation of nutritional values of shiitake mushroom (Lentinus edodes) stipes. J. Food Meas. Charact. 2018, 12, 2012-2019. [CrossRef]

22. Heleno, S.A.; Prieto, M.A.; Barros, L.; Rodrigues, A.; Barreiro, M.F.; Ferreira, I.C. Optimization of microwave-assisted extraction of ergosterol from Agaricus bisporus L. by-products using response surface methodology. Food Bioprod. Process. 2016, 100, 25-35. [CrossRef]

23. Ahmed, M.; Abdullah, N.; Shuib, A.S.; Abdul Razak, S. Influence of raw polysaccharide extract from mushroom stalk waste on growth and $\mathrm{pH}$ perturbation induced-stress in Nile tilapia, Oreochromis niloticus. Aquaculture 2017, 468, 60-70. [CrossRef]

24. Zou, H.; Evrendilek, F.; Liu, J.; Buyukada, M. Combustion behaviors of pileus and stipe parts of Lentinus edodes using thermogravimetric-mass spectrometry and Fourier transform infrared spectroscopy analyses: Thermal conversion, kinetic, thermodynamic, gas emission and optimization analyses. Bioresour. Technol. 2019, 288, 121481. [CrossRef] [PubMed]

25. Bernal, M.P.; Sommer, S.G.; Chadwick, D.; Qing, C.; Guoxue, L.; Michel, F.C. Chapter Three-Current Approaches and Future Trends in Compost Quality Criteria for Agronomic, Environmental, and Human Health Benefits. In Advances in Agronomy; Sparks, D.L., Ed.; Academic Press: Cambridge, MA, USA, 2017; Volume 144, pp. 143-233.

26. ASTM E1756-08; Standard Test Method for Determination of Total Solids in Biomass. ASTM International: West Conshohocken, PA, USA, 2015.

27. Cai, J.; He, Y.; Yu, X.; Banks, S.W.; Yang, Y.; Zhang, X.; Yu, Y.; Liu, R.; Bridgwater, A.V. Review of physicochemical properties and analytical characterization of lignocellulosic biomass. Renew. Sustain. Energy Rev. 2017, 76, 309-322. [CrossRef]

28. Chew, K.W.; Chia, S.R.; Yap, Y.J.; Ling, T.C.; Tao, Y.; Show, P.L. Densification of food waste compost: Effects of moisture content and dairy powder waste additives on pellet quality. Process Saf. Environ. Prot. 2018, 116, 780-786. [CrossRef]

29. Azargohar, R.; Soleimani, M.; Nosran, S.; Bond, T.; Karunakaran, C.; Dalai, A.K.; Tabil, L.G. Thermo-physical characterization of torrefied fuel pellet from co-pelletization of canola hulls and meal. Ind. Crops Prod. 2019, 128, 424-435. [CrossRef]

30. Zajonc, O.; Frydrych, J.; Jezerska, L. Pelletization of Compost for Energy Utilization. IERI Procedia 2014, 8, 2-10. [CrossRef]

31. Finimundy, T.C.; Dillon, A.J.P.; Henriques, J.A.P.; Ely, M.R. A review on general nutritional compounds and pharmacological properties of the Lentinula edodes mushroom. Food Nutr. Sci. 2014, 5, 1095-1105. [CrossRef]

32. Yu, H.; Xie, B.; Khan, R.; Shen, G. The changes in carbon, nitrogen components and humic substances during organic-inorganic aerobic co-composting. Bioresour. Technol. 2019, 271, 228-235. [CrossRef]

33. Chalk, P.M.; Inácio, C.T.; Chen, D. An overview of contemporary advances in the usage of $15 \mathrm{~N}$ natural abundance $(\delta 15 \mathrm{~N})$ as a tracer of agro-ecosystem N cycle processes that impact the environment. Agric. Ecosyst. Environ. 2019, 283, 106570. [CrossRef]

34. Wang, X.; Zhai, M.; Wang, Z.; Dong, P.; Lv, W.; Liu, R. Carbonization and combustion characteristics of palm fiber. Fuel 2018, 227, 21-26. [CrossRef]

35. Akratos, C.S.; Tekerlekopoulou, A.G.; Vasiliadou, I.A.; Vayenas, D.V. Chapter 8-Cocomposting of olive mill waste for the production of soil amendments. In Olive Mill Waste; Galanakis, C.M., Ed.; Academic Press: Cambridge, MA, USA, 2017; pp. 161-182. 
36. Xiang, Y.; Jun, Q.; Zhen, L.; Yaning, L.; Anlong, Z.; Yingkun, S. Research on the infrared spectroscopy of spent mushroom compost. Nat. Envir. Pollut. Technol. 2016, 15, 701.

37. Parmar, R.; Kumar, D. Studyof chemical composition in wild edible mushroom Pleurotus cornucopiae (Paulet) from Himachal Pradesh, India by using Fourier transforms infrared spectrometry (FTIR), Gas chromatography-mass spectrometry (GCMS) and X-ray fluorescence (XRF). Biol. Forum Int. J. 2015, 7, 1057-1066.

38. Li, X.; Pang, Y.; Zhang, R. Compositional changes of cottonseed hull substrate during P. ostreatus growth and the effects on the feeding value of the spent substrate. Bioresour. Technol. 2001, 80, 157-161. [CrossRef]

39. Grube, M.; Lin, J.G.; Lee, P.H.; Kokorevicha, S. Evaluation of sewage sludge-based compost by FT-IR spectroscopy. Geoderma 2006, 130, 324-333. [CrossRef]

40. Singh, B.; Avci, U.; Eichler Inwood, S.E.; Grimson, M.J.; Landgraf, J.; Mohnen, D.; Sørensen, I.; Wilkerson, C.G.; Willats, W.G.T.; Haigler, C.H. A specialized outer layer of the primary cell wall joins elongating cotton fibers into tissue-like bundles. Plant Physiol. 2009, 150, 684-699. [CrossRef]

41. Abidi, N.; Cabrales, L.; Haigler, C.H. Changes in the cell wall and cellulose content of developing cotton fibers investigated by FTIR spectroscopy. Carbohydr. Polym. 2014, 100, 9-16. [CrossRef] [PubMed]

42. Lou, Z.; Sun, Y.; Zhou, X.; Baig, S.A.; Hu, B.; Xu, X. Composition variability of spent mushroom substrates during continuous cultivation, composting process and their effects on mineral nitrogen transformation in soil. Geoderma 2017, 307, 30-37. [CrossRef]

43. Ahmad, M.S.; Mehmood, M.A.; Liu, C.-G.; Tawab, A.; Bai, F.-W.; Sakdaronnarong, C.; Xu, J.; Rahimuddin, S.A.; Gull, M. Bioenergy potential of Wolffia arrhiza appraised through pyrolysis, kinetics, thermodynamics parameters and TG-FTIR-MS study of the evolved gases. Bioresour. Technol. 2018, 253, 297-303. [CrossRef]

44. Pua, F.-L.; Subari, M.S.; Ean, L.-W.; Krishnan, S.G. Characterization of biomass fuel pellets made from Malaysia tea waste and oil palm empty fruit bunch. Mater. Today. Proc. 2020, 31, 187-190. [CrossRef]

45. Gao, L.; Volpe, M.; Lucian, M.; Fiori, L.; Goldfarb, J.L. Does hydrothermal carbonization as a biomass pretreatment reduce fuel segregation of coal-biomass blends during oxidation? Energy Convers. Manag. 2019, 181, 93-104. [CrossRef]

46. Wang, T.; Li, Y.; Zhang, J.; Zhao, J.; Liu, Y.; Sun, L.; Liu, B.; Mao, H.; Lin, Y.; Li, W.; et al. Evaluation of the potential of pelletized biomass from different municipal solid wastes for use as solid fuel. Waste Manag. 2018, 74, 260-266. [CrossRef] [PubMed]

47. Tumuluru, J.S. Effect of process variables on the density and durability of the pellets made from high moisture corn stover. Biosys. Eng. 2014, 119, 44-57. [CrossRef]

48. Emadi, B.; Iroba, K.L.; Tabil, L.G. Effect of polymer plastic binder on mechanical, storage and combustion characteristics of torrefied and pelletized herbaceous biomass. ApEn 2017, 198, 312-319. [CrossRef]

49. Pradhan, P.; Mahajani, S.M.; Arora, A. Pilot scale production of fuel pellets from waste biomass leaves: Effect of milling size on pelletization process and pellet quality. Fuel 2021, 285, 119145. [CrossRef]

50. Qin, Y.; Zhao, Z.; Wiltowski, T.; Aloqaili, M.; Liang, Y. Investigation of Co-Gasification Reactivity of Torrefied Jatropha Seed Cake with Illinois\# 6 Coal Char. BioResources 2016, 11, 7624-7636.

51. Nobre, C.; Gonçalves, M.; Mendes, B.; Vilarinho, C.; Teixeira, J. Torrefaction Effects on Composition and Quality of Biomass Wastes Pellets. In Proceedings of the 3rd International Conference on Wastes: Solutions, Treatments and Opportunities, Viana Do Castelo, Portugal, 14-16 September 2015; pp. 171-176.

52. Jia, G. Combustion Characteristics and Kinetic Analysis of Biomass Pellet Fuel Using Thermogravimetric Analysis. Processes 2021, 9, 868. [CrossRef]

53. Waqas, M.; Almeelbi, T.; Nizami, A.-S. Resource recovery of food waste through continuous thermophilic in-vessel composting Environ. Sci. Pollut. Res. 2018, 25, 5212-5222. [CrossRef]

54. Ungureanu, N.; Vladut, V.; Voicu, G.; Dinca, M.-N.; Zăbavă, B.-Ș. Influence of biomass moisture content on pellet propertiesReview. Eng. Rural. Dev. 2018, 17, 1876-1883. [CrossRef]

55. Sharma, H.B.; Dubey, B.K. Binderless fuel pellets from hydrothermal carbonization of municipal yard waste: Effect of severity factor on the hydrochar pellets properties. J. Clean. Prod. 2020, 277, 124295. [CrossRef]

56. Liu, Z.; Liu, X.e.; Fei, B.; Jiang, Z.; Cai, Z.; Yu, Y. The properties of pellets from mixing bamboo and rice straw. Renew. Energy 2013, 55, 1-5. [CrossRef]

57. Zafari, A.; Kianmehr, M.H. Factors affecting mechanical properties of biomass pellet from compost. Environ. Technol. 2014, 35, 478-486. [CrossRef] [PubMed]

58. Ayilara, M.S.; Olanrewaju, O.S.; Babalola, O.O.; Odeyemi, O. Waste Management through Composting: Challenges and Potentials. Sustainability 2020, 12, 4456. [CrossRef]

59. Malakahmad, A.; Idrus, N.B.; Abualqumboz, M.S.; Yavari, S.; Kutty, S.R.M. In-vessel co-composting of yard waste and food waste: An approach for sustainable waste management in Cameron Highlands, Malaysia. Int. J. Recyl. Org. Waste Agric. 2017, 6, 149-157. [CrossRef]

60. Abasalizadeh, H.; Fathi Gerdelidani, A.; Khalaj, S.; Jalili Aramesh, S. Evaluation of environmental performance of the Starclean composter machine in converting the wet wastes into compost. J. Environ. Sci. Technol. 2017. 